\title{
Prevalence Of Alcohol Consumption In First-Year Romanian Medical Students And Its Association With Cardiovascular Risk Factors
}

\author{
Adriana Gherbon, MD \\ Romulus Timar, $M D, P h D$
}

2nd Department of Internal Medicine, Discipline of Diabetes, Nutrition and Metabolic Diseases "Victor Babes” University of Medicine and Pharmacy, , Timisoara, Romania

Mirela Frandes, PhD

Department of Biostatistics and Medical Informatics, "Victor Babes"

University of Medicine and Pharmacy, Timisoara, Romania

\section{Marioara Nicula, PhD}

Dorel Dronca, PhD

Mirela Ahmadi, PhD

Banat University of Agricultural Sciences and Veterinary Medicine "King Mihai I of Romania" from Timisoara, Faculty of Bioengineering of Animal Resources, Timisoara, Romania

Doi:10.19044/esj.2021.v17n21p337

Submitted: 28 February 2021

Accepted: 22 June 2021

Published: 30 June 2021
Copyright 2021 Author(s)

Under Creative Commons BY-NC-ND 4.0 OPEN ACCESS

Cite As:

Gherbon A., Timar R., Frandes M., Nicula M., Dronca D. \& Ahmadi M. (2021). Prevalence Of Alcohol Consumption In First-Year Romanian Medical Students And Its Association With Cardiovascular Risk Factors. European Scientific Journal, ESJ, 17(21), 337.

https://doi.org/10.19044/esj.2021.v17n21p337

\begin{abstract}
Alcohol is the third risk factor for premature disease and death for the general population of the European Union (EU) after smoking and high blood pressure. In the case of young people, they consume alcohol based on the desire to explore, sometimes associating it with recreational drugs use, thus increasing the risk of negative consequences. The objective of this study was to assess the prevalence of alcohol consumption and its association with other cardiovascular risk factors in first-year medical students. The studied lot consisted of 434 first-year medical students, $30.18 \%$ boys, and $69.82 \%$ girls,
\end{abstract}


with the mean age of $19.48 \pm 0.53$ years. The methods included the administration of a questionnaire (CORT 2004 questionnaire on health risk behaviors in first-year medical students) for assessing both alcohol consumption and stress state, as well as blood pressure determination, and anthropometric parameters. The prevalence of alcohol consumption among first-year medical students was $22.58 \%$, with a net prevalence of male gender $(57.25 \% \mathrm{M}$ versus $7.59 \% \mathrm{~F})(\mathrm{p}<0.001, \mathrm{X} 2=129.02)$. The main reasons for alcohol consumption were the festive and official occasions and the desire to integrate into the group. People with whom they prefer to drink alcohol were friends, colleagues, and family. The age at which most people began to consume alcohol was 13-14 years old, and the favorite drink was beer among boys and wine among the girls. Regarding the cardiovascular risk factors, positive correlations were obtained between alcohol and smoking, increased consumption of bread, sedentary lifestyle, and increased body mass index. Students need to be educated from the first year of study on the long-term consequences of alcohol consumption related to the development of the cardiovascular disease, and further studies are needed to see if educational programs really reduce the prevalence of alcohol consumption.

Key Words: Alcohol, First-Year Medical Students, Cardiovascular Risk Factors

\section{Introduction}

In the field of organic chemistry, alcohols represent hydroxyl organic compounds containing a hydroxyl functional group attached to a saturated carbon atom. The most commonly used alcohols are methanol or methyl alcohol and ethanol or ethyl alcohol [Ioniță, 2008].

The term alcohol refers to any beverage containing ethanol. Alcohol is the third risk factor for premature disease and death for the general population of the European Union (EU) after smoking and high blood pressure (WHO) [WHO, 2014; Lammerich et al, 2016].

Alcohol can cause a range of conditions: neuropsychiatric disorders (epilepsy, depression, anxiety, etc.), digestive diseases (alcoholic liver cirrhosis, acute and chronic pancreatitis, and alcoholic gastropathy), cancers (digestive tract, and breast), cardiovascular disorders (ischemic, hemorrhage stroke, hypertension), increase lead in the blood [Nicula et al, 2017] etc. It is also responsible for the vast majority of traffic accidents, especially for young people [WHO, 2016]. In addition to health effects, excessive alcohol consumption can cause relational problems (deterioration of family relationships, separation, divorce, abuse and neglect of children), loss of friends, material difficulties, job loss, loss of housing, social exclusion, legal 
problems (fines, imprisonment), inappropriate sexual behavior (unprotected sex, rape, unwanted pregnancy) [WHO, 2014].

Excessive alcohol consumption is considered to be the consumption of at least 60 grams of pure alcohol in men or 40 grams of pure alcohol in women at least once in the last 30 days (WHO) [Steffens et al, 2016] or at least 5 alcoholic beverages with one occasionally, once in the last 30 days [Hibell et al, 2012].

Romania ranks 3rd in the EU by the amount of alcohol consumed and second in the countries with the most harmful consumption pattern. As for the type of beverage consumed, beer is in the first place, followed by wine (60\%) and spirits ( 40\%) [WHO, 2014; RARHA, 2016].

In the case of young people, they consume alcohol from the desire to explore, sometimes associating with recreational drug use, thus increasing the risk of negative consequences. Thus, one of ten deaths among young women aged 15-29 and one in four deaths among young men was found to be due to alcohol [Commission of European Communities, 2006].

\section{Experimental part \\ Material and method}

The study was cross-sectional, non-interventional, based on the CORT 2004 questionnaire on health risk behaviors in first-year medical students [Vlaicu, 2007]. The Cardiovascular Risk Factors Identification was based on the European Guidelines for the Prevention of Cardiovascular Disease (2016) [European Guidelines on cardiovascular disease prevention in clinical practice, 2016].

The inclusion criteria were:

- First-year Romanian medical students

The exclusion criteria:

- Medical students from other years

- Refuse to participate to the study

All the students from the first year wanted to participate to the study.

None of these students refused the participation. The large prevalence of female students was related to the fact that predominantly female students are pursuing a medical school.

The study of these eating habits in medical students was part of a larger study on cardiovascular risk factors in young people, i.e., those aged from 18 to 19 years. Because only those in the first year were at this age, only they were asked to participate in the study.

The criteria for assessing the unhealthy diet were: breakfast consumption under 7 days/week, consumption of more than 6-11 servings/day bread and cereals, under 3-4 servings/day fresh fruit and vegetables, over 3 days/week or daily foods rich in fat, over 3 days/ week or regular high-refined 
food. These criteria were approved by the Ethics Committee of the Victor Babes University of Medicine and Pharmacy Timisoara.

For all students, were determinate the anthropometric parameters represented by height, weight, body mass index (BMI), and abdominal circumference (AC). Also, we determinate blood pressure (BP). BMI was calculated using the weight/height ${ }^{2}$ formula, being overweight the persons with BMI between $25-29.9 \mathrm{~kg} / \mathrm{m}^{2}$ and obese those with BMI $\geq 30 \mathrm{~kg} / \mathrm{m}^{2}$. For AC we considered normal values for women $<80 \mathrm{~cm}$ and for men $<94 \mathrm{~cm}$. $\mathrm{BP}$ was determined using a conventional blood pressure cuff, considered as a risk factor values of SBP above $140 \mathrm{mmHg}$. Highly normal values (130-139 $\mathrm{mmHg}$ ) were also considered a cardiovascular risk factor. The Perceived Stress Questionnaire was used to assess the stress level [Băban, 1998]. The study was approved by the Ethics Committee of the "Victor Babes" University of Medicine and Pharmacy, Timisoara. All participants gave informed consent to participate in the study.

Measured data were analyzed using the IBM SPSS Statistics v.20 software. Numerical continuous variables were characterized by the mean and standard deviation (SD), and nominal ones by frequency and percentage. For all variables, the $95 \%$ confidence interval was calculated. A comparison of the category-type variables was performed by applying the chi-square test or the Fisher exact test, and the continuous ones by the unpaired t-test or Wilcoxon test. The criteria for a variable to be considered a risk factor were OR > 1 (95\% $\mathrm{CI}>1$ ). The OR calculations were performed using logistic regressions. The statistical significance threshold was considered $\mathrm{p}<0.05$.

\section{Results}

The study group consisted of 434 first-year medical students, 30.18\% boys, and $69.82 \%$ girls, with the mean age of $19.48 \pm 0.53$ years, age range 18-20 years. Approximately one quarter (22.58\%) of first-year medical students who responded to the questionnaire acknowledged that they were drinking alcohol. Regarding the gender distribution, a net prevalence of male gender was found $(57.25 \% \mathrm{M}$ versus $7.59 \% \mathrm{~F})\left(\mathrm{X}^{2}=129.02, \mathrm{p}<0.001\right)$.

The main reasons for alcohol consumption in first-year medical students were the festive and official occasions, i.e., and because they wanted to integrate into the group (Fig. 1). 


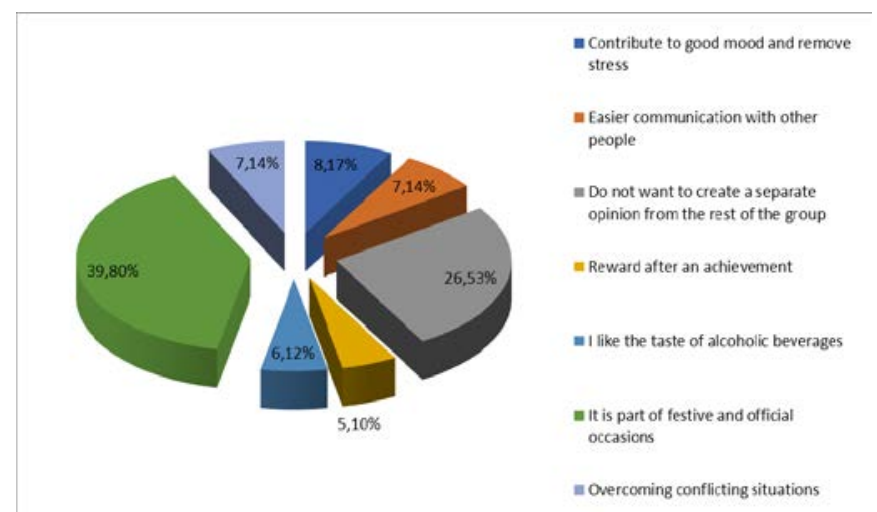

Figure 1. Reasons for Drinking Alcohol in First-Year Medical Students

Concerning people with whom alcohol is consumed, consumption is usually preferred with friends, colleagues, but also with family (Fig. 2).

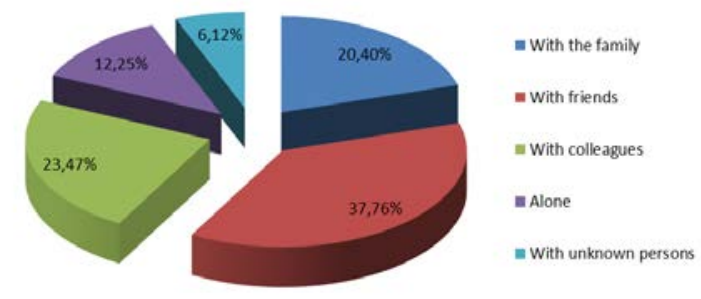

Figure 2. People with Whom Alcohol is Consumed by First-Year Medical Students

The onset age of first alcohol consumption was predominantly between 13-14 years, followed by 15-16 years, and 17 years respectively (Fig. 3).

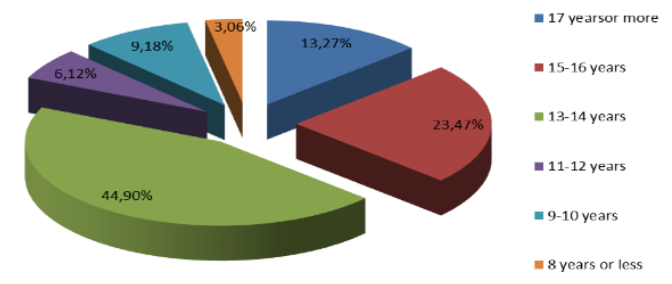

Figure 3. Age of First Alcohol Consumption in First-Year Medical Students 
As for the type of alcoholic beverages, in the study, boys prefer beer, and girls' wine (Fig. 4).

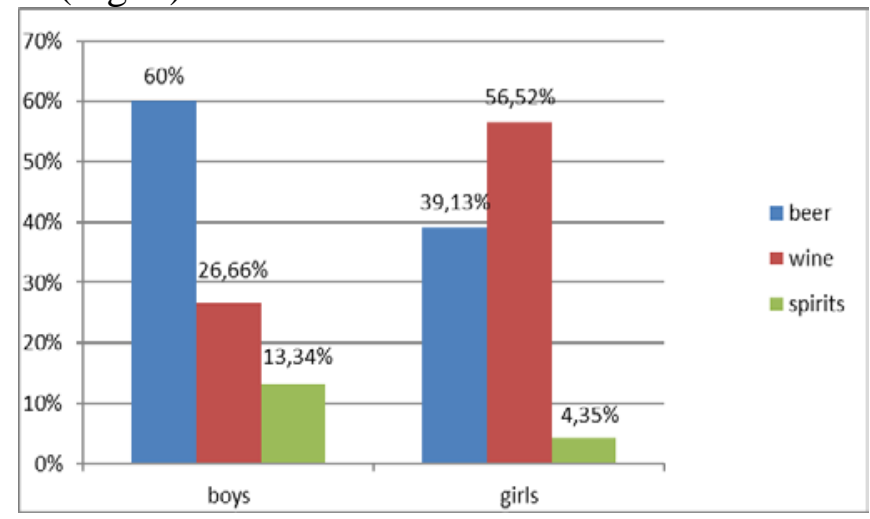

Figure 4. Type of Alcoholic Beverages Consumed by First Year Medical Students

It was followed also the association between alcohol consumption and cardiovascular risk factors, and the results are in the table below (Table I).

Table I. The correlation between alcohol consumption and cardiovascular risk factors

\begin{tabular}{|c|c|c|c|c|c|c|c|c|c|c|c|}
\hline \multirow[t]{3}{*}{ Parameters } & \multicolumn{4}{|c|}{ Consumers (C) } & \multicolumn{4}{|c|}{ Non - consumers (NC) } & \multirow{2}{*}{$\begin{array}{l}\text { OR } \\
{[95 \% \mathrm{CI}]} \\
\mathrm{C} \text { vs. NC } \\
\end{array}$} & \multirow{2}{*}{$\begin{array}{l}\text { OR } \\
{[95 \% \mathrm{CI}]} \\
\mathrm{C} \text { vs. NC } \\
\end{array}$} & \multirow{2}{*}{$\begin{array}{l}\text { OR } \\
{[95 \% \mathrm{CI}]} \\
\text { C vs. NC } \\
\end{array}$} \\
\hline & \multicolumn{2}{|c|}{$F=23$} & \multicolumn{2}{|c|}{$\mathrm{M}=75$} & \multicolumn{2}{|c|}{$F=280$} & \multicolumn{2}{|c|}{$\mathrm{M}=56$} & & & \\
\hline & Yes & No & Yes & No & Yes & No & Yes & No & & $\mathrm{F}$ & $\mathrm{M}$ \\
\hline Smoking & 12 & 11 & 34 & 41 & 58 & 222 & 18 & 38 & $\begin{array}{l}\text { OR = } \\
3.02 \\
{[1.88-} \\
4.85] \\
p<0.001\end{array}$ & $\begin{array}{l}\text { OR }=4.17 \\
{[1.75-} \\
9.95] \\
p=0.0012\end{array}$ & $\begin{array}{l}\mathrm{OR}=1.75 \\
{[0.85-3.60]} \\
\mathrm{p}=0.12\end{array}$ \\
\hline $\begin{array}{l}\text { Saturated } \\
\text { fats }\end{array}$ & 13 & 10 & 38 & 37 & 134 & 146 & 26 & 30 & $\begin{array}{l}\text { OR }= \\
1.19 \\
{[0.76-} \\
1.87] \\
p=0.44\end{array}$ & $\begin{array}{l}\text { OR = 1.41 } \\
{[0.60-} \\
3.33] \\
p=0.42\end{array}$ & $\begin{array}{l}\mathrm{OR}=1.18 \\
{[0.59-2.37]} \\
\mathrm{p}=0.63\end{array}$ \\
\hline $\begin{array}{l}\text { Refined } \\
\text { carbohydrat } \\
\text { es }\end{array}$ & 13 & 10 & 64 & 11 & 229 & 51 & 47 & 9 & $\begin{array}{l}\text { OR }= \\
0.79 \\
{[0.45-} \\
1.39] \\
p=0.42\end{array}$ & $\begin{array}{l}\text { OR }=0.28 \\
{[0.12-} \\
0.69] \\
p=0.0057\end{array}$ & $\begin{array}{l}\mathrm{OR}=0.11 \\
{[0.42-2.9]} \\
\mathrm{p}=0.82\end{array}$ \\
\hline $\begin{array}{l}\text { Increased } \\
\text { bread } \\
\text { consumptio } \\
\text { n }\end{array}$ & 4 & 19 & 37 & 38 & 41 & 239 & 16 & 40 & $\begin{array}{l}\text { OR } \\
3.52 \\
{[2.15-} \\
5.75] \\
p \quad< \\
0.0001\end{array}$ & $\begin{array}{l}\text { OR }=1.22 \\
{[0.39-} \\
3.79] \\
p=0.72\end{array}$ & $\begin{array}{l}\mathrm{OR}=2.43 \\
{[1.16-5.07]} \\
\mathrm{p}=0.0178\end{array}$ \\
\hline $\begin{array}{l}\text { Fruits and } \\
\text { vegetables }\end{array}$ & 9 & 14 & 20 & 55 & 75 & 205 & 8 & 48 & $\begin{array}{l}\text { OR = } \\
0.78 \\
{[0.47-} \\
1.28]\end{array}$ & $\begin{array}{l}\text { OR }=0.56 \\
{[0.23-} \\
1.36] \\
p=0.20\end{array}$ & $\begin{array}{l}\mathrm{OR}=0.45 \\
{[0.18-1.13]} \\
\mathrm{p}=0.09\end{array}$ \\
\hline
\end{tabular}




\begin{tabular}{|c|c|c|c|c|c|c|c|c|c|c|c|}
\hline & & & & & & & & & $\mathrm{p}=0.33$ & & \\
\hline $\begin{array}{l}\text { Short } \\
\text { sleeping } \\
\text { duration }\end{array}$ & 14 & 9 & 50 & 25 & 196 & 84 & 46 & 10 & $\begin{array}{l}\text { OR }= \\
1.36 \\
{[0.84-} \\
2.20] \\
p=0.20\end{array}$ & $\begin{array}{l}\text { OR }=1.50 \\
{[0.62-} \\
3.60] \\
p=0.36\end{array}$ & $\begin{array}{l}\mathrm{OR}=2.3 \\
{[0.99-5.30]} \\
p=0.0507\end{array}$ \\
\hline $\begin{array}{l}\text { Sedentary } \\
\text { physical } \\
\text { activity }\end{array}$ & 3 & 20 & 12 & 63 & 90 & 190 & 16 & 40 & $\begin{array}{l}\text { OR } \\
2.55 \\
{[1.40-} \\
4.62] \\
\mathrm{p} \\
0.0021=\end{array}$ & $\begin{array}{l}\text { OR = 3.15 } \\
{[0.91-} \\
10.9] \\
p=0.068\end{array}$ & $\begin{array}{l}\mathrm{OR}=2.1 \\
{[0.9-4.8]} \\
\mathrm{p}=0.08\end{array}$ \\
\hline $\begin{array}{l}\text { Increased } \\
\text { stress levels }\end{array}$ & 16 & 7 & 42 & 33 & 207 & 73 & 49 & 7 & $\begin{array}{l}\text { OR }= \\
0.45 \\
{[0.28-} \\
0.72] \\
p \\
0.0011=\end{array}$ & $\begin{array}{l}\text { OR }=0.80 \\
{[0.31-} \\
2.03] \\
p=0.64\end{array}$ & $\begin{array}{l}\mathrm{OR}=0.18 \\
{[0.07-0.45]} \\
\mathrm{p}=0.0003\end{array}$ \\
\hline $\begin{array}{l}\text { Absence of } \\
\text { breakfast }\end{array}$ & 7 & 16 & 14 & 61 & 50 & 230 & 11 & 45 & $\begin{array}{l}\text { OR = } \\
0.81 \\
{[0.46-} \\
1.41] \\
p=0.46\end{array}$ & $\begin{array}{l}\text { OR =0.49 } \\
{[0.19-} \\
1.27] \\
p=0.14\end{array}$ & $\begin{array}{l}\mathrm{OR}=1.06 \\
{[0.44-2.56]} \\
p=0.88\end{array}$ \\
\hline Weight gain & 2 & 21 & 4 & 71 & 11 & 269 & 5 & 51 & $\begin{array}{l}\text { OR = } \\
1.30 \\
{[0.49-} \\
3.42] \\
p=0.59\end{array}$ & $\begin{array}{l}\text { OR = 2.32 } \\
{[0.4811 .20} \\
] \\
p=0.29\end{array}$ & $\begin{array}{l}\text { OR }=0.57 \\
{[0.14-2.24]} \\
p=0.42\end{array}$ \\
\hline $\mathrm{AC}$ & 1 & 22 & 12 & 63 & 21 & 259 & 8 & 48 & $\begin{array}{l}\text { OR }= \\
1.61 \\
{[0.80-} \\
3.25] \\
p=0.17\end{array}$ & $\begin{array}{l}\text { OR = 0.56 } \\
{[0.07-} \\
4.36] \\
p=0.58\end{array}$ & $\begin{array}{l}\mathrm{OR}=1.14 \\
{[0.43-3.01]} \\
\mathrm{p}=0.78\end{array}$ \\
\hline $\begin{array}{l}\text { BMI } \\
\text { increased }\end{array}$ & 2 & 21 & 23 & 52 & 29 & 251 & 20 & 36 & $\begin{array}{l}\text { OR } \\
2.00 \\
{[1.16-} \\
3.46] \\
\mathrm{p} \\
0.0125\end{array}=$ & $\begin{array}{l}\text { OR }=0.82 \\
{[0.18-} \\
3.69] \\
p=0.80\end{array}$ & $\begin{array}{l}\text { OR }=0.79 \\
{[0.38-1.65]} \\
p=0.54\end{array}$ \\
\hline Mean SBP & 1 & 22 & 12 & 63 & 15 & 265 & 19 & 37 & $\begin{array}{l}\text { OR }= \\
1.35 \\
{[0.68-} \\
2.68] \\
p=0.37\end{array}$ & $\begin{array}{l}\text { OR =0.76 } \\
{[0.009-} \\
6.07] \\
p=0.80\end{array}$ & $\begin{array}{l}\mathrm{OR}=0.37 \\
{[0.16-0.84]} \\
p=0.019\end{array}$ \\
\hline
\end{tabular}

Discussions

Approximately one quarter (22.58\%) of first-year medical students who responded to the questionnaire acknowledged that they were drinking alcohol. Worldwide, the prevalence of alcohol consumption in adolescents is 
48\% and varies from 66\% (Austria, Cyprus, Denmark, and Greece) to 9\% in Iceland [Steffens et al, 2016].

Almost all young Europeans aged 15-16 years old (80\% except Iceland) have consumed alcohol at least once in life, with variations between 35 and 96\%, with the highest consumption rates in the Czech Republic, Albania and Hungary, and the smallest in Iceland, Macedonia and Norway [Steffens et al, 2016].

Regarding the gender distribution, a net prevalence of male gender was found (57.25\% M versus 7.59\% F) $\left(\mathrm{X}^{2}=129.02\right.$, $\left.\mathrm{p}<0.001\right)$. Worldwide, boys are more likely to drink alcohol than girls. The exception is the Belgian young women in Flanders (77\% compared to $51 \%$ in Albania and Macedonia) [Steffens et al, 2016].

The main reasons for alcohol consumption in first-year medical students were the festive and official occasions, i.e., and because they wanted to integrate into the group (Fig.1). In the first year of college, young people try to create new friends and to belong to a particular group. As a result, it is possible to consume alcohol at the pressure of the group or to integrate into the group to be recognized by them. Most agree to follow the group's rules because they want to avoid loneliness and the feeling of associated sadness. They also look for friends in a way to escape from the environment in which they live, a situation that does not offer the opportunity to reach their ideals and the need for self-reliance.

When alcohol is consumed, adolescents believe they can do whatever they want because of their skills but represent the disinhibiting effect of alcohol. After the impact of alcohol ceases, there is a feeling of helplessness, a lack of hope more pronounced than before. One of the reasons for alcohol consumption is to overcome conflicting situations from the family, school, or friends (7.14\%), and for others, alcohol is a way to forget the hardships of life, to get a sense of calm, or just fun. They consume alcohol in bars, discos, or other locations, sometimes just out of curiosity. In the studied group, 8.17\% of the subjects' state that they have chosen to consume alcohol because consumption contributes to a good mood and relieves stress, and 6.12\% motivates their use by enjoying the taste of alcoholic beverages. 5.1\% consume alcohol to reward after an achievement. All these reasons are pretexts to get out of everyday life, to feel good with others.

A study performed on 1359 young Romanian adults aged 18-30 years from urban environments including the main university centers showed that the most common reasons they first tried alcohol consumption were curiosity (67.8 \%), to be like peers (17.9\%), and adult influence (6.5\%). Also, $72.5 \%$ consumed alcohol only on special occasions/holidays, $19.4 \%$ on weekends, $4.8 \%$ three to four times per week, and $0.4 \%$ on a daily basis. Most of them 
drank with a group of friends (62.3\%) and $9.7 \%$ of participants drank because of poor concentration, or problems at work/school [Rada et al, 2016].

In the world, $64 \%$ of adolescents and young people appreciate alcohol as a means of entertainment, while $48 \%$ drink to forget about the problems. Less than half of young people (42\%) admitted that alcohol could have harmful effects on health. One-third of young people are aware that alcohol can cause inappropriate behavior, and one in five thinks they cannot control the amount of ingested alcohol. About 6 out of ten adolescents are involved in physical violence and 4\% in unprotected sexual activities [Van Hoof, 2012].

Concerning people with whom alcohol is consumed, consumption is usually preferred with friends, colleagues, but also with family (Fig. 2). In a smaller proportion, it is also preferable solitary consumption or with unknown people, which shows a lower desire to join the norms of a group, and a need to solve daily problems through the use of alcohol.

The onset age of first alcohol consumption was predominantly between 13-14 years, followed by 15-16 years, and 17 years respectively (Fig. 3). Worldwide, about $60 \%$ of adolescents began to consume alcohol before the age of 13 , and $12 \%$ experienced the first episode of intoxication at this age. In a study performed in Romania on 1980 students, regarding alcohol consumption, $67 \%$ make use of it and started drinking when they were 14 or 15 years old [Petrelli et al, 2018].

Excessive alcohol consumption is more common among young people in the Nordic countries (39\%) [Steffens et al, 2016]. In terms of gender distribution, excess alcohol consumption is slightly decreasing among boys (43\% in 2011 versus 45\% in 2007) and a slight increase among girls (35\% in 2003 versus 38\% in 2011) [Steffens et al, 2016].

In Romania, nation statistics showed that about $84 \%$ of the boys and $12 \%$ of the 16-year-old girls consumed an alcoholic drink at least once in their life, decreasing from 2007 (81\%), 2003 (88\%) and 1999 (85\%) and below the EU average (87\%). Approximately 6\% of adolescents consumed their first alcoholic beverages before the age of 9 years or 17 years of age, respectively. In the case of boys, the prevalence of alcohol consumption increases with age, while in girls, it is not influenced by age. A quarter of the 18-34-year-old were victims of physical violence associated with alcohol. In the past ten years, was decreased both the percentage of adolescents who regularly consume alcohol (52\% in 2007, 47\% in 2015) and the frequency of excessive consumption episodes (27\% in 1999, 36\% in 2011, 12\% in 2015) [National month of information about the effects of alcohol consumption - situation analysis, 2018].

Romania is considered a country with moderate alcohol consumption among European countries, but consumption is likely to be much higher, and 
many young people will not recognize it [Hibell et al, 2009; INSP. CNEPSS, 2015; and Ministry of Health, 2011].

As for the type of alcoholic beverages, in the study, boys prefer beer, and girls' wine (Fig. 4). At the European level, existing data show that boys consume beer, while girls prefer spirits [Steffens et al, 2016; Hibell et al, 2012]. Beer consumption continues to register in Romania, a downward trend observed since 2003, reaching 53.9\% in 2015 (nation statistics). Beer consumption in Romania is above the average consumption found in ESPAD countries, with the European average being 38.2\% in 2015 (nation statistics). The wine consumption among Romanian adolescents is also slightly decreasing in 2015 compared to 2011 (from 45\% to 43.2\% of students) but above the ESPAD average of $31.4 \%$ (nation statistics). Consumed strengths in the last month in 2015 were at a value similar to that observed in the previous study - 30\% in 2015, compared to 31\% in 2011, being below the European average of - 32.1\% [National Anti-Drug Agency ESPAD, 2015].

The current study also followed the correlation between alcohol consumption and cardiovascular risk factors (Table I).

Positive correlations between alcohol and smoking increased consumption of bread, sedentary lifestyle, and increased BMI are observed. In the function of gender, positive relationships were obtained in female between alcohol and smoking. The students preferred to consume ready-meals or fastfoods products because of convenience or to avoid cooking, leading to an increase consumption of bread [Sprake, 2017].

Generally, it was found that people who consume alcohol are smokers, have a low tendency to physical activity, and consume more portions of bread, which over time, will lead to weight gain and cardiovascular disease. Smoking and alcohol are considered risk behaviors, resulting in time to the increasing prevalence of depressive syndrome [Cohn et al, 2014]. Alcohol consumption is accompanied by smoking cigarettes only in male students from Romania [Zadarko-Domaradzka et al, 2018]. Also, people with higher BMI have an increased tendency to drink alcohol because they are depressed, and they usually consume alone, have no friends or colleagues.

Girls associate alcohol consumption with fun, with a group of colleagues and friends, many of them are smoking at the same time. Boys usually consume more alcohol, with the tendency to eat at the same time, especially more portions of bread and cereals. A study in Denmark showed a correlation between sedentary lifestyle and alcohol consumption, both sexes with sedentary activity, presenting a 1.5 to 2-time higher risk of consuming alcohol [Ejsing et al, 2015]. A college study on first-year students showed that moderate alcohol consumption increased appetite, followed by fast food choices and increased BMI over time [Lloyd-Richardson et al, 2008]. 


\section{Conclusion}

During the first years of college, students connect new friends, being influenced by the group they belong to. At the same time, they continue to experience alcohol consumption, smoking, and even drug use. This study shows that alcohol consumption is associated with some cardiovascular risk factors (smoking, sedentary lifestyle, unhealthy diet, increased BMI), over time, determining the occurrence of cardiovascular disease.

Students need to be educated from the first year of study on the longterm consequences of alcohol consumption related to the development of the cardiovascular disease, and further studies are needed to see if educational programs really reduce the prevalence of alcohol consumption.

\section{References:}

1. Băban, A. (1998). Stress and personality. Cluj University Press Publishing House, ISBN 973-9354-35-1

2. Cohn, A.M., Cobb, C., Hagman, T.B., Cameron, A., Ehlke, S., Mitchell, N.J. (2014). Implicit alcohol cognitions in risky drinking nicotine users with and without co-morbid major depressive disorder, Addictive Behaviors. 39(4):797-802.

3. Commission of European Communities. Communication From The Commission To The Council, The European Parliament, The European Economic And Social Committee And The Committee Of The Regions. An EU strategy to support Member States in reducing alcohol related harm. (f.e.) Brussels. (2006)

4. Ejsing, L.K., Becker, U., Tolstrup, J.S., Flensborg-Madsen, T. (2015). Physical Activity and Risk of Alcohol Use Disorders: Results from a Prospective Cohort Study. Alcohol and Alcoholism. 50(2):206-212.

5. European Guidelines on cardiovascular disease prevention in clinical practice: The Sixth Joint Task Force of the European Society of Cardiology and Other Societies on Cardiovascular Disease Prevention in Clinical Practice (constituted by representatives of 10 societies and by invited experts) Developed with the special contribution of the European Association for Cardiovascular Prevention \& Rehabilitation (EACPR). European Heart Journal. (2016). Volume 37, Issue 29, Pages 2315-2381.

6. Hibell, B., Guttmorsson, U., Ahlstrom, S., Balakieva, O., Bjamson, T., Kokkavi, A. et all. (2012). The 2011 ESPAD Report. Stockholm, Sweden: The Swedish Council for Information on Alcohol and Other Drugs

7. INSP. CNEPSS. National Report on the Health of Children and Youth in Romania 2015. (2015). "Carol Davila" University Publishing House, Bucharest 
8. Ioniță, P. (2008). Chemistry course of organic compounds with simple functions. The University of Bucharest

9. Lammerich, S., Kullas, M. (2016). Alcohol Strategy 2016-2022 A feasible tool for consumer protection?

10. Lloyd-Richardson, E.E., Lucero, M.L., DiBello, J.R., Jacobson, A.E., and Wing, R.R. (2008). The Relationship Between Alcohol Use, Eating Habits and Weight Change in College Freshmen. Eat Behav. 9(4): 504-508.

11. Ministry of Health. (2011). Note on the issue of alcohol consumption as a health risk factor: current situation and objectives

12. National Anti-Drug Agency ESPAD 2015. (2016). National study in schools on tobacco, alcohol and drug use. ESPAD - 2015. RESEARCH REPORT Bucharest, Romania

13. National month of information about the effects of alcohol consumption - situation analysis. (2018)

14. Nicula, M., Păcală, N., Ștef, L., Pet, I., Dronca, D., Gherbon, A., Ahmadi, M. (2017). In vivo Experiments (Carassius Gibelio Bloch of Natural Products Protection of Antagonistic Effects of Lead on Iron. Chemistry Journal. vol.68, no 12, pag. $2747-2751$

15. Petrelli F, Scuri S, Tanzi E, Nguyễn TTC, Grappasonni I. Lifestyles and discomfort in a sample of young Romanian students. J Prev Med Hyg. 2018 Sep 28;59(3): E230-E235. doi: 10.15167/24214248/jpmh2018.59.3.985. PMID: 30397680; PMCID: PMC6196370.

16. Rada, C., Ispas, A.T. Alcohol consumption and accentuated personality traits among young adults in Romania: a cross-sectional study. Subst Abuse Treat Prev Policy 11, 36 (2016). https://doi.org/10.1186/s13011-016-0080

17. RARHA. (2016). Comparative monitoring of alcohol epidemiology across the EU. Baseline assessment and suggestions for future action. Synthesis report.

18. Sprake, E., Lavin, J., Grabowski, P., Russell, J., Featherstone, M., \& Barker, M. (2017). Eating habits associated with body weight gain in female university students. British Food Journal.

19. Steffens, R. \& Sarrazin, D. (2016). Guidance to reduce alcohol-related harm for young people. Background paper. Münster: LWLCoordination Office for Drug Related Issues

20. Van Hoof, J.J., Moll, M. (2012). Adolescent Alcohol Consumption in Romania: A Blueprint for Measuring Alcohol (mis) Use. Journal of Research and Social Intervention. (37):77-90

21. Vlaicu B. Risk behaviors in teenagers from Timis county. Timisoara: Eurobit, 2007. 
22. WHO. (2014). Alcohol and inequities. Guidance for addressing inequities in alcohol-realed harm. Copenhaga: WHO Regional Office for Europe

23. WHO. (2016). World health Statistics 2016: monitoring health for the SDGs. France

24. Zadarko-Domaradzka M., Barabasz Z., Sobolewski M., NiziołBabiarz E., Penar-Zadarko, B., Szybisty A., and Zadark E. Alcohol Consumption and Risky Drinking Patterns among College Students from Selected Countries of the Carpathian Euroregion. Biomed Res Int 2018;2018:6084541 